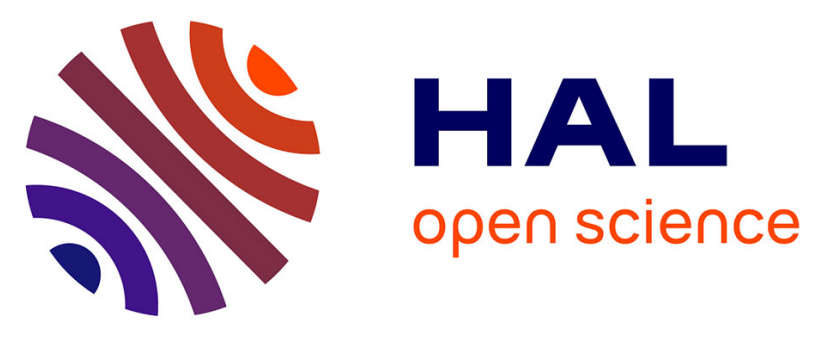

\title{
ENHANCEMENT OF MULTIFIBER BEAM ELEMENTS IN THE CASE OF REINFORCED CONCRETE STRUCTURES FOR TAKING INTO ACCOUNT THE LATERAL CONFINEMENT OF CONCRETE DUE TO STIRRUP
}

N Khoder, S. Grange, Y. Sieffert

\section{To cite this version:}

N Khoder, S. Grange, Y. Sieffert. ENHANCEMENT OF MULTIFIBER BEAM ELEMENTS IN THE CASE OF REINFORCED CONCRETE STRUCTURES FOR TAKING INTO ACCOUNT THE LATERAL CONFINEMENT OF CONCRETE DUE TO STIRRUP. COMPDYN 20176 th ECCOMAS Thematic Conference on Computational Methods in Structural Dynamics and Earthquake Engineerin, Jun 2017, Rhodes, Greece. hal-02004317

\section{HAL Id: hal-02004317 https://hal.science/hal-02004317}

Submitted on 1 Feb 2019

HAL is a multi-disciplinary open access archive for the deposit and dissemination of scientific research documents, whether they are published or not. The documents may come from teaching and research institutions in France or abroad, or from public or private research centers.
L'archive ouverte pluridisciplinaire HAL, est destinée au dépôt et à la diffusion de documents scientifiques de niveau recherche, publiés ou non, émanant des établissements d'enseignement et de recherche français ou étrangers, des laboratoires publics ou privés. 


\title{
ENHANCEMENT OF MULTIFIBER BEAM ELEMENTS IN THE CASE OF REINFORCED CONCRETE STRUCTURES FOR TAKING INTO ACCOUNT THE LATERAL CONFINEMENT OF CONCRETE DUE TO STIRRUP
}

\author{
N. Khoder ${ }^{1,2}$, S. Grange ${ }^{2}$, and Y. Sieffert ${ }^{1}$ \\ ${ }^{1}$ Univ. Grenoble Alpes INF*, CNRS, 3SR, F-3800 Grenoble, France \\ e-mail: \{natalia.khoder, yannick.sieffert\}@3sr-grenoble.fr \\ ${ }^{2}$ Univ Lyon, INSA-Lyon, SMS-ID, F-69621, France \\ e-mail: stephane.grange@insa-lyon.fr
}

Keywords: Confinement, Stirrups, Finite Elements, Multifiber Beam Elements, Reinforced Concrete.

\begin{abstract}
To assess the seismic vulnerability of existing reinforced concrete structures, a large number of degrees of freedom is involved. Consequently, efficient numerical tools are required. In the case of slender elements, enhanced beam elements have been developed to try to introduce shear effects, but in these models, the transverse steel is sometimes taken into consideration with approximated manner or often not at all. However, as shown by some experimental tests, the amount of transverse reinforcement triggers significantly the behavior of beam elements, especially under cyclic loading. Thus, the main goal of this work is to investigate solutions for an enhanced multifiber beam element accounting for vertical stretching of the cross section, occurring due to the presence of transverse reinforcement. The efficiency of the proposed modeling strategies is tested with results obtained from tension and flexure tests conducted on an elastic linear material.
\end{abstract}

${ }^{*}$ Institute of Engineering Univ. Grenoble Alpes 


\section{INTRODUCTION}

To study the seismic vulnerability of existing reinforced concrete structures, numerical computations at the structural scale able to account for material non-linearities are needed. An alternative to full solid models, which are too costly, is the use of multifiber beam elements. The latter one combines the advantages of high computational speed with an increased accuracy for nonlinear materials. It consists on adding a two dimensional section at the Gauss point of the element.

In addition, a variety of approaches have been developed to try to introduce shear effects, such as the one proposed by [1], but which cannot be applied to reinforced concrete elements. More recently, [2, 3] developed a nonlinear multifiber beam model which provides robust results by the introduction of warping in the case of reinforced concrete beams. Moreover, in the above mentioned works, the transverse steel is not taken into account. However, as shown by some experimental tests conducted by [4], the amount of transverse reinforcement triggers significantly the behavior of beam elements, especially under cyclic loading. The numerical formulation of [5] which is adapted to reinforced concrete applications takes into account the transverse reinforcement but works only in 2D. Thus, the main goal of this work is to investigate solutions for an enhanced multifiber beam element accounting for vertical stretching of the cross section, occurring due to the presence of stirrups.

\section{FORMULATION OF THE ENHANCED MULTIFIBER BEAM ELEMENT}

A 2D multifiber Timoshenko beam, displacement-based, element has been developed. The main assumption considered herein is that the full displacement of any fiber in the cross-section can be approximated by the sum of the plane section displacement field $\left(\mathbf{u}^{P}\right)$, obtained from Timoshenko's beam theory, and a new displacement field that enables the section to distort and warp $\left(\mathbf{u}^{w}\right)$. The distortion field has one transverse component, $u_{y}^{w}$, which stands for the distortion of the section. Thus, the total displacement at any material point of the cross section is given by the following equation:

$$
\mathbf{u}=\mathbf{u}^{P}+\mathbf{u}^{w}=\underbrace{\left[\begin{array}{c}
U_{x}-y \theta_{z} \\
U_{y}
\end{array}\right]}_{u^{P}}+\underbrace{\left[\begin{array}{c}
0 \\
u_{y}^{w}(x, y)
\end{array}\right]}_{u^{w}}
$$

The complete strain will be formed by the sum of the plane strain field $\epsilon^{P}$ and the warp strain $\epsilon^{w}$. Following on from the kinematics given by equation 1, the linearised strain tensor reads:

$$
\epsilon=\frac{1}{2}(\operatorname{grad}(u)+\operatorname{grad}(u))^{T}=\epsilon^{\mathbf{P}}\left(\mathbf{u}^{P}\right)+\epsilon^{\mathbf{w}}\left(\mathbf{u}^{w}\right)
$$

Equation 3 expresses the non linear constitutive law:

$$
\sigma=\hat{\sigma}\left(\epsilon^{p}, \epsilon^{w}\right)
$$

\subsection{Governing equations}

Beam equilibrium is written in its weak form by equation 4 . In addition, the plane section displacement $u^{p}$ and the distortion one $u^{w}$ assumed to be orthogonal, the projection of the weak form equilibrium on these two subspaces lead to two equilibrium equations (equation 5). The first one representing the classical equilibrium of the beam element, and the second one being 
the equilibrium equation of the cross section. F denotes the external forces and $P^{w}$ the forces coming from constrained warping at the beam ends.

$$
\begin{gathered}
\int_{\Omega} \epsilon^{* T} \sigma d \Omega=U^{* T} F_{\text {ext }} \\
\Leftrightarrow\left\{\begin{array}{c}
\int_{\Omega} \delta \epsilon^{p T} \hat{\sigma}\left(\epsilon^{p}, \epsilon^{w}\right) d \Omega=F \\
\int_{\Omega} \delta \epsilon^{w T} \hat{\sigma}\left(\epsilon^{p}, \epsilon^{w}\right) d \Omega=P^{w}
\end{array}\right.
\end{gathered}
$$

\subsection{Use of a new Timoshenko element with internal degrees of freedom}

The use of linear interpolation functions leads to shear locking problems. In order to overcome this phenomenon, several authors have developed numerical models based on the use of higher-order interpolation functions or functions depending on the material properties [6]. The disadvantage of the latter ones is that they are not updated during the nonlinear computations. Thus, the solution will be exact in elasticity but approximated after initiation of the damage. Recently, a new multifiber beam element, with internal degrees of freedom, has been developed by [7] and has been chosen to be introduced in our model.

Caillerie's element is presented by figure 1. Each of the two nodes has 3 degrees of freedom $(u, v, \theta)$. This element presents in addition, 4 internal degrees of freedom $\left(\Delta v_{1}, \Delta \theta, \Delta v_{2}\right.$ and $\Delta u)$. Cubic interpolation functions $\left(H_{R}^{1}, H_{R}^{2}, L_{R}^{1}, L_{R}^{2}\right)$ are used for transverse diplacements and quadratic ones $\left(L_{R}^{\prime 1}, L_{R}^{\prime 2}, M_{R}^{3}\right)$ for rotations. These functions are independent of material properties.

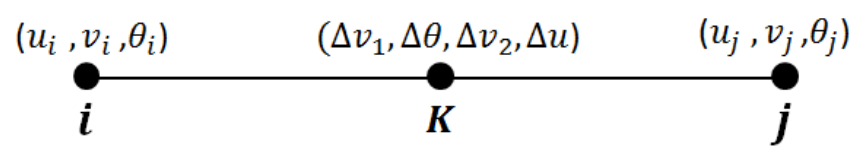

Figure 1: Definition of the degrees of freedom in the 2D version of the Caillerie's beam element

The generalized displacement field is therefore written as follows:

$$
\begin{aligned}
U_{x} & =N_{1}(\xi) u_{1}+N_{2}(\xi) \Delta u+N_{3}(\xi) u_{2} \\
U_{y} & =H_{R}^{1} v_{1}+H_{R}^{2} v_{2}+L_{R}^{1} \Delta v_{1}+L_{R}^{2} \Delta v_{2} \\
\theta_{z} & =L_{R}^{\prime 1} \theta_{1}+L_{R}^{\prime 2} \theta_{2}+M_{R}^{3} \Delta \theta
\end{aligned}
$$

Where $N_{1}, N_{2}$ and $N_{3}$ are given by equation 7 :

$$
\left\{\begin{array}{l}
N_{1}=\frac{1}{2} \xi(\xi-1) \\
N_{2}=1-\xi^{2} \\
N_{3}=\frac{1}{2} \xi(\xi+1)
\end{array}\right.
$$




\subsection{Spatial discretization}

The deformations of the plane section $\epsilon^{P}$, can be expressed as a function of the generalized deformations, $e_{s}$, as shown in equation 8 :

$$
\begin{gathered}
\epsilon^{P}=\left[\begin{array}{c}
\epsilon_{x x}^{P} \\
\epsilon_{y y}^{P} \\
\gamma_{x y}^{P}
\end{array}\right]=\underbrace{\left[\begin{array}{ccc}
1 & 0 & -y \\
0 & 0 & 0 \\
0 & 1 & 0
\end{array}\right]}_{a_{s}(y)} \underbrace{\left[\begin{array}{c}
\frac{d U_{x}}{d x} \\
\frac{d U_{y}}{d x}-\theta_{z} \\
\frac{d \theta_{z}}{d x}
\end{array}\right]}_{e_{s}} \\
\epsilon^{P}=a_{s}(y) B_{p} U^{e}
\end{gathered}
$$

The displacements of a standard 2D beam element consist of two translations $\mathrm{u}$ and $\mathrm{v}$, in $\mathrm{x}$ and $\mathrm{y}$ directions respectively, and one rotation $\theta_{z}$ about $\mathrm{z}$ axis. These are functions of position $\mathrm{x}$ along the element axis and are collected in displacement vector $U^{e} . B_{p}$ gathers the derivatives of the interpolation functions related to longitudinal spatial discretization.

In addition, the $2 \mathrm{D}$ beam element, in the present study, is enhanced with a warping-distortion displacement $u_{y}^{w}$, given by the following expression:

$$
u^{w}(x, y)=u_{y}^{w}=c(x) \varphi(y)
$$

Hence, the warping strains can be written in the form:

$$
\left[\begin{array}{c}
\epsilon_{x x}^{w} \\
\epsilon_{y y}^{w} \\
\gamma_{x y}^{w}
\end{array}\right]=\left[\begin{array}{c}
\frac{\partial u_{x}^{w}}{\partial x} \\
\frac{\partial u_{y}^{w}}{\partial y} \\
\frac{\partial u_{x}^{w}}{\partial y}+\frac{\partial u_{y}^{w}}{\partial x}
\end{array}\right]=\left[\begin{array}{c}
0 \\
c(x) \frac{d \varphi(y)}{d y} \\
\frac{d c(x)}{d x} \varphi(y)
\end{array}\right]=\underbrace{\left[\begin{array}{cc}
0 & 0 \\
0 & \frac{d \varphi}{d y} \\
\varphi & 0
\end{array}\right]}_{a_{w}} \underbrace{\left[\begin{array}{c}
\frac{d c}{d x} \\
c
\end{array}\right]}_{B_{w} W^{e}}
$$

Where $W_{e}$ gathers the warping degrees of freedom, and $B_{w}$ the longitudinal interpolation functions and their derivatives. As for the components of $a_{s}$ and $a_{w}$, they are computed at the Gauss points of each section which is discretized by using six-nodes triangular elements.

After discretization of the beam and the section domains, the formulation leads to two coupled systems of nonlinear equations to solve for the classical beam nodal displacements and for the additional warping displacements. The element stiffness matrix $K_{e l}$ as well as the internal element force vector $f_{e}$ are given by the following equations:

$$
\begin{gathered}
K_{e l}=\left[\begin{array}{cc}
\int_{\Omega^{e}} B_{p}^{T} a_{s}^{T} K_{m a t} a_{s} B_{p} d \Omega^{e} & \int_{\Omega^{e}} B_{p}^{T} a_{s}^{T} K_{m a t} a_{w} B_{w} d \Omega^{e} \\
\int_{\Omega^{e}} B_{w}{ }^{T} a_{w}{ }^{T} K_{m a t} a_{s} B_{p} d \Omega^{e} & \int_{\Omega^{e}} B_{w}{ }^{T} a_{w}{ }^{T} K_{m a t} a_{w} B_{w} d \Omega^{e}
\end{array}\right] \\
f_{e}=\left[\begin{array}{l}
\int_{L^{e}} B_{p}^{T}\left(\int_{S} a_{s}^{T} \hat{\sigma}\left(\epsilon^{P}, \epsilon^{w}\right) d S\right) d x \\
\int_{L^{e}} B_{w}{ }^{T}\left(\int_{S} a_{w}{ }^{T} \hat{\sigma}\left(\epsilon^{P}, \epsilon^{w}\right) d S\right) d x
\end{array}\right]
\end{gathered}
$$




\section{RESULTS}

A simple cantilever beam submitted to transversal diplacement and then to an axial displacement has been modelled numerically by using 30 Timoshenko multifiber beam elements. The cross section of the beam is considered to be $0.15 \mathrm{~m} \times 0.15 \mathrm{~m}$ area and is meshed using 72 six-nodes quadratic triangles (TRI6). It is made of an homogeneous material considered to be elastic linear.

Figure 2 shows the flexure test that has been conducted as well as a representation of the discretized cross section. All warping degrees of freedom have been blocked at the fixed end of the beam.
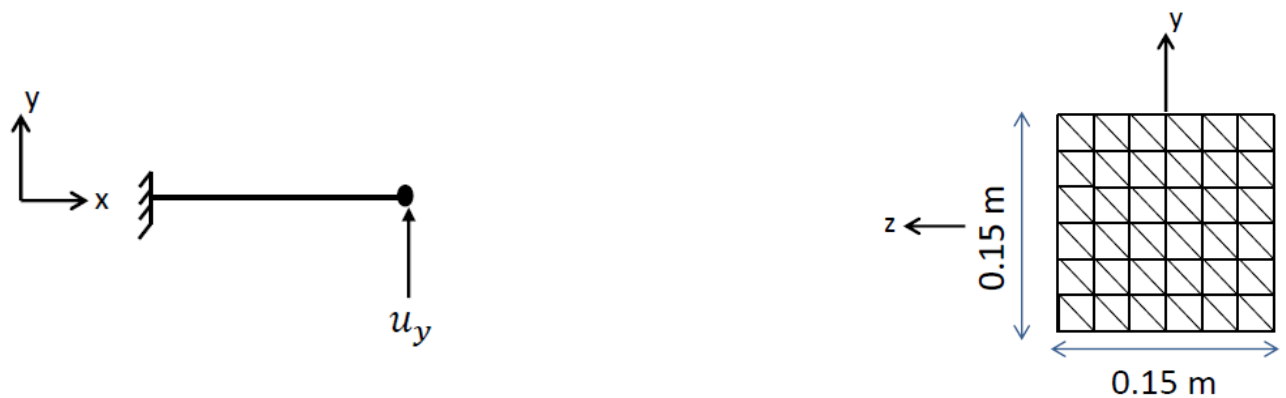

Figure 2: Flexure test (left), Discretized cross section (right)

A 2D finite element model meshed with 492 TRI6 elements has also been conducted in order to compare the variation of the lateral normal stresses as well as the transverse displacement with the ones obtained using the enhanced multifiber beam element.

Figure 3 shows the evolution of transverse displacement maps, and a good matching between the computed warping displacement and the 2D finite element solution can be seen. The maximum local error for transverse displacement is of the order of $0.011 \%$ for flexure at a section situated next to the fixed end.

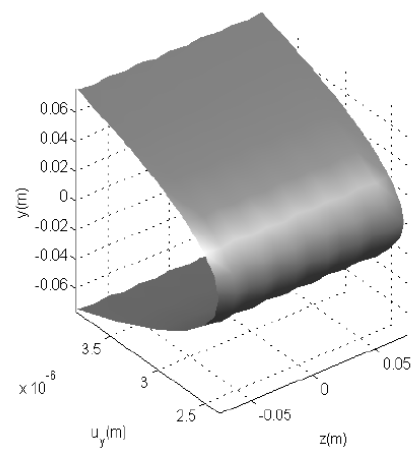

Multifiber beam element

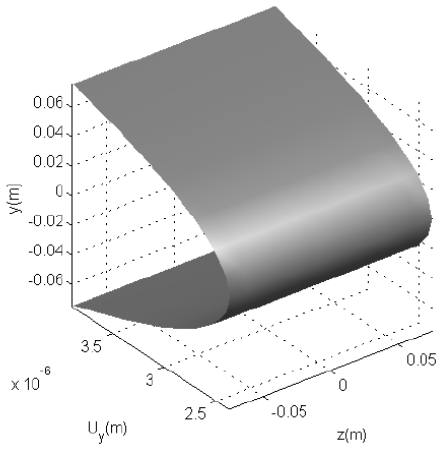

2D Finite element

Figure 3: Transverse displacement maps obtained with the enhanced model and the 2D finite element, at a section situated next to the fixed end

Also, the variation of transversal stresses $\sigma_{y y}$ computed at each fiber of the cross section, with respect to the length of the beam, as well as section maps of $\sigma_{y y}$ obtained at different 
positions: next to the fixed and free ends are displayed in figure 4. These results prove that the equilibrium state is reached and the enhanced developed model works well in the linear elastic phase.

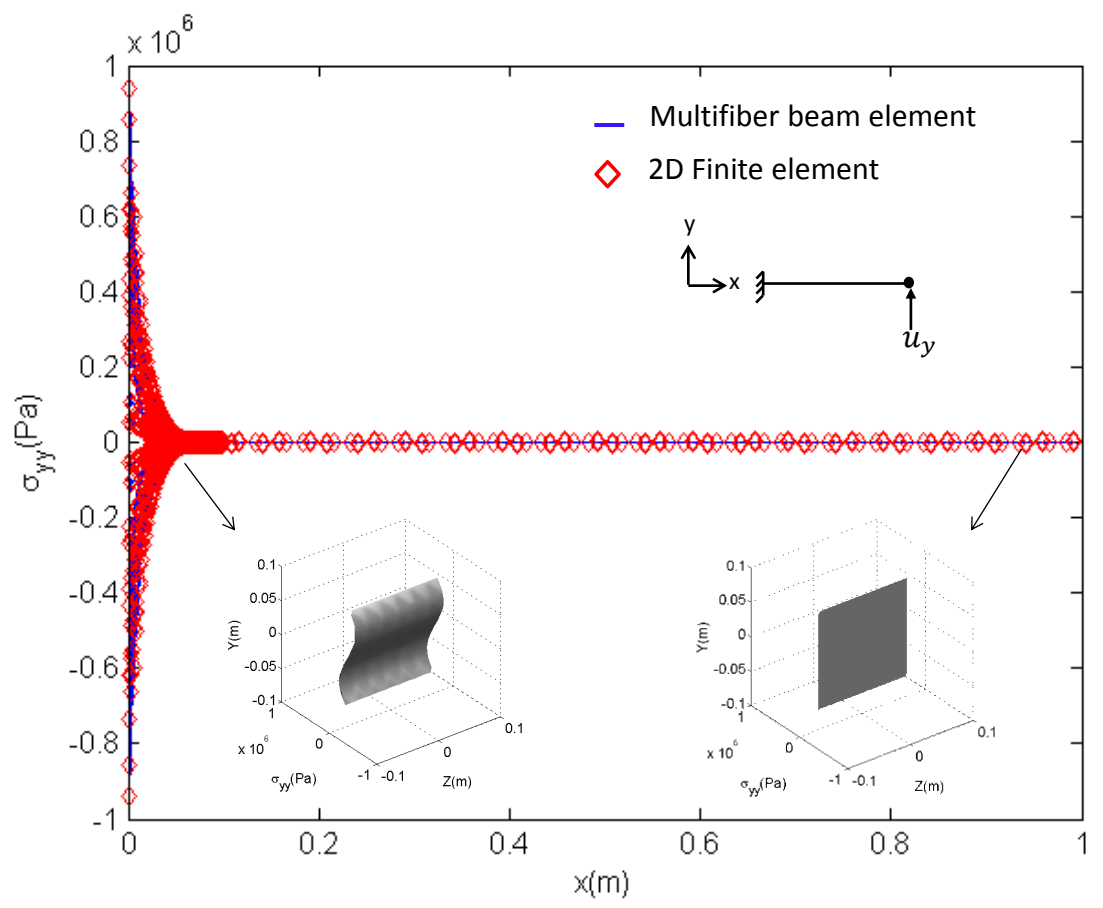

Figure 4: Variation of the transversal stresses $\sigma_{y y}$ with respect to the length of the beam subjected to flexure test. Section maps of $\sigma_{y y}$ at different positions of the beam.

\section{CONCLUSION}

This paper proposes a method to account for transversal stretching of the cross section. The efficiency of the proposed modeling strategies is tested with results obtained from tension and flexure tests conducted on an homogeneous elastic linear material. The results prove that the equilibrium state is reached and the enhanced developed model works well in the linear elastic phase. The ongoing works aim at modelling transverse steel as well as implementing an existing constitutive law for concrete under monotonic and cyclic loadings and hence study the nonlinear response of structural elements subjected to transverse shear.

\section{REFERENCES}

[1] V. Le Corvec, Nonlinear 3d frame element with multi-axial coupling under consideration of local effects, PhD Thesis, University of California, Berkeley, 2012.

[2] S. Capdevielle, S. Grange, F. Dufour, C. Desprez, A multifiber beam model coupling torsional warping and damage for reinforced concrete structures, European Journal of Environmental and Civil Engineering, vol. 20 (8), p. 914-935, 2016. 
[3] S. Capdevielle, Introduction du gauchissement dans les éléments finis multifibres pour la modélisation non linéaire des structures en béton armé, PhD Thesis, Université de Grenoble Alpes, 2016.

[4] D. Cusson, P. Paultre, Stress-Strain model for confined high-strength concrete, American Society Of Civil Engineers, 1995.

[5] S. Mohr, J. Bairán, A. Marí, A frame element model for the analysis of reinforced concrete structures under shear and bending, Engineering structures, vol. 32 (12), p. 3936-3954, 2010.

[6] Z. Friedman, Z. Kosmatka, An improved two-node timoshenko beam finite element, Computers and structures, vol. 47 (3), p. 473-481, 1993.

[7] D. Caillerie, P. Kotronis, R. Cybulski, A timoshenko finite element straight beam with internal degrees of freedom, International Journal For Numerical And Analytical Methods In Geomechanics, 2015. 